\title{
A RETÓRICA TIPOGRÁFICA NOS TEMPOS DA WEB
}

\author{
Kherlianne de Sá Barbosa \\ Universidade Federal do Ceará \\ kherlianne@gmail.com \\ Carlos Eduardo Brito Novais \\ Universidade Federal do Ceará \\ eduardonovais@virtual.ufc.br \\ Georgia da Cruz Pereira \\ Universidade Federal do Ceará \\ georgia@virtual.ufc.br
}

Resumo: O presente artigo buscou analisar a atual situação da tipografia no meio digital e na web. O ponto de partida se deu pela a análise bibliográfica da evolução tipográfica ao decorrer dos séculos até a sua chegada no meio digital e na web. Além da análise histórica da tipografia, também foi realizado uma análise semiótica. Neste sentido, espera-se abrir a discussão sobre até onde a tipografia deve ser limitada para a utilização na web, causando também a limitação da utilização dos tipos pelos designers. A partir do levantamento bibliográfico realizado neste artigo analisou-se as perdas e os ganhos da tipografia na web e também foram sugeridos novos campos de pesquisa para as barreiras encontradas.

Palavras-chave: Tipografia na Web. Retórica tipográfica. Inovação tipográfica. Semiótica.

\begin{abstract}
This article aimed to analyze the current situation of typography in the digital media and the web. The starting point was given by the bibliographical analysis of typographic evolution throughout the ages until his arrival in the digital media and the web. In addition to historical analysis of typography was also performed a semiotic analysis. In this regard, it is expected to open the discussion to where the typography should be limited for use on the web, also causing the restriction of the use of types by designers. From the literature survey in this article the losses and gains of typography in the web was evaluated and and was also suggested new research about the difficulties found.
\end{abstract}

Keywords: Typography in the web. Typographic rhetoric. Tyupographic Innovation. Semiotics. 


\section{INTRODUÇÃO}

A constante evolução da tipografia ao longo dos anos possibilitou avanços na sua prática, mas também proporcionou entraves que seriam vencidos a cada século. Com a entrada dos computadores pessoais em cena que se iniciou na década de 1980, a possibilidade de criar tipografias foi aumentada, possibilitando também que mais pessoas pudessem realizar esse trabalho. Ao mesmo tempo em que isso possibilitou uma diversificação e maior acesso a fontes e ao seu uso, houve uma preocupação com os padrões de leitura e legibilidade para o ambiente que viria a ser bastante valorizado alguns anos depois, que seria a web.

A pesquisa tem por objetivo analisar as perdas e as conquistas da tipografia no ambiente digital, fornecendo possibilidades para libertar o design da Safe Fonts, fontes que eram e são permitidas para a utilização na web sem que ocorra pirataria, e possibilitar um ambiente na web mais interativo com a tipografia e o layout. Nesse processo será observado como a tipografia teve sua importância como signo, passando a comunicar mais que o texto, até o momento que ela é padronizada pela web e acaba regredindo novamente. No decorrer do trabalho, será feita uma revisão bibliográfica buscando compreender o papel da tipografia como signo semiótico e a sua aplicação com as influências durante os séculos, chegando até o meio digital e o nascimento do usuário, onde o leitor passa a desempenhar outro papel e passa a ser peça fundamental para a criação de peças gráficas (LUPTON, 2006).

Durante o levantamento de dados perguntas como: "Porque a utilização na web está mudando a tipografia?" "Quais as possibilidades depois da entrada do CSS na estilização?" foram levantadas com o intuito de mostrar os ganhos e limitações da fonte ao decorrer do tempo. Dessa forma, procuramos nessa pesquisa os pontos positivos e negativos da entrada da tipografia na web e de que maneira poderia isso poderia contribuir para a libertação da tipografia do seu uso em sites, quebrando barreiras e possibilitando novas ideias.

O referencial teórico será disposto de duas formas. A primeira parte tem objetivo de mostrar a evolução da tipografia até o ponto que ela ganha espaço no meio digital. A segunda parte o referencial teórico tem como objetivo mostrar as barreiras que a tipografia encontrou entrando no ambiente digital e uma análise de perdas e ganhos, no intuito de desenvolver considerações para integrar o tema discutido.

\section{EVOLUÇÃO DA COMPREENSÃO DA TIPOGRAFIA COMO SIGNO VISUAL}

Em seu princípio, a escrita veio como uma maneira de comunicar de forma mais eficiente o que antes era transmitido oralmente, preservando conhecimentos, experiências e pensamentos que foram arduamente conquistados, assim como também foi importante para controlar as atividades comerciais que até então eram negociadas oralmente (MEGGS e PURVIS, 2009). Ela, então, foi representada com um conjunto de signos inicialmente pictográficos e, posteriormente, fonéticos, que representavam outros signos, fossem eles objetos, ideias, dentre outros (LUPTON E MILLER, 2013). A partir de representações iniciadas em pedras, tábuas, pergaminhos, até em livros feitos à mão, uma revolução começou a surgir no registro de escrito da informação que começou a ganhar espaço, apesar do tempo e custo de um livro desenvolvido por um copista. 
No século XIII, com as universidades já em ascensão, houve um aumento no mercados dos livros, demandando novas formas mais rápidas e econômicas no processo de produção de livros (MEGGS e PURVIS, ibid.). Coube ao tipógrafo alemão Gutenberg a invenção dos tipos móveis na Europa, onde cada caractere era esculpido em auto-relevo de maneira que as matrizes de caractere poderiam compor facilmente uma matriz de página e também podendo ser reorganizadas facilmente em novas matrizes de página. Com essa inovação da imprensa a produção de livros tornou-se mais barata e rápida.

Nesse período os livros da época tinham caráter informativo (FONSECA, 2008), ferramentas que facilitassem a leitura eram produzidas, culminando no surgimento dos estilos tipográficos como bold e itálico. Os tipógrafos tiveram que adequar a fonte apenas para a leitura, produzindo então livros com fontes menores, mais compactas e que requeriam menos material (FONSECA, ibid.).

Durante muitos anos a comunicação por caractere foi valorizada e com a função de transmitir informações, mostrando-se como um representante da fala, podendo ser categorizada como um acompanhante do texto, uma modalidade de escrita, como citado por Cauduro (1998). Warde (1932) também categorizava a leitura da tipografia de três maneiras para o texto ela poderia ser apenas para facilitar a leitura, ou poderia ser lida e percebida ou poderia comunicar mais que o texto.

O surgimento e o avanço da litografia no período do art nouveau fez com que as mensagens tomassem outro sentido além de apenas ser lido. Essa vertente obteve vários seguidores anos após anos e o caractere começou a ser valorizado como forma de comunicar, passando-se a uma ideia de compreensão do valor retórico da tipografia (NOJIMA, 2007). Esse pensamento retórico teve como objetivo questionar os valores que estavam sendo utilizados, eram padrões que estavam estigmatizados por possuírem mesmo padrão visual. Os padrões como o Estilo Suíço ou Internacional estavam sendo indagados, passaram-se anos e a sua influência permanecia forte na tipografia.

Derrida (1967) também realizou uma crítica ao pensamento que até então era forte em relação a tipografia e semiologia, criticou o modo de pensar de Saussure, onde valorizava mais a fala que a sua forma de representação. Derrida acreditava que a Semiótica e a Tipografia trabalhavam juntas, que possuíam uma relação de via dupla, sendo a escrita uma forma de representação ativa que influenciava no leitor e que iria desconstruir o pensamento da tipografia pelo viés linguístico.

Saussure (1916) incialmente acreditava que a escrita influenciava a fala. Trabalhou por diversos anos para que o caractere fosse apenas um elemento representacional para a comunicação, que não substituía a fala, mas atuava como uma representação gráfica das expressões fonéticas. Esse pensamento foi questionado por diversas vezes nos estudos linguísticos. E quando se passa a analisar a linguagem escrita não somente pelo viés semântico, mas a partir das suas características significativas como tipografia, ela deixa de ser apenas uma representação gráfica de leitura e ganha um caráter de significante primeiro, um símbolo cujas características de significação partem de sua composição material, da sintaxe de seus elementos e adquirem sentidos pragmáticos. A tipografia agora poderia ser analisada de diversas formas, sendo alguma delas como um signo linguístico, com relação ao objeto representado, um signo simbólico quando ela tiver relação com o objeto estabelecido por convenção, dentre outros. 
O pensamento de Saussure seria contraposto por ideias que transformariam significantemente a atuação e importância da tipografia no design nos anos subsequentes, bem como ampliariam a percepção da construção retórica tipográfica e a quebra de padrões estilísticos com finalidades de significação.

\section{A RETÓRICA TIPOGRÁFICA EM MEIO AO NASCIMENTO DO USUÁRIO}

Barthes (2004) falava que o texto não tinha por fim o autor, ele afirmava que o texto quando escrito visava o leitor e este seria o ponto chave para a multiplicidade de interpretações do texto. A partir dessa afirmação, o leitor passa a ter um papel importante para a criação do significado, fazendo com que vários designers adotassem essa ideia a partir dos anos 80 e 90 (LUPTON, 2006).

No momento que a tipografia foi redefinida como discurso, Nojima (2007) discorreu sobre o discurso que Mccoy implodiu com a dicotomia do ver e do ler, possibilitando que as fontes fossem vistas e fossem notadas como signos. Com isso possibilitou aos leitores que criassem suas próprias interpretações, valorizando a ambiguidade e a complexidade.

Brumberg (2003) mostrou como o texto poderia ser percebido de diversas formas pelo leitor, gerando para os designers uma série de confusões em relação a disposição da tipografia com o meio de leitura. Brumberg (2003) ainda afirmou que a tipografia vai ficar de acordo com o leitor, ou seja, para cada pessoa vai existir uma fonte adequada, fazendo com que o design tente buscar cada vez mais uma forma de abranger todos esses usuários. Essa ideia de que o usuário contribui de forma significante também é constatada por Lupton (2006), onde também faz um análise de como a disposição do texto, seja pela fonte ou pelo espaço que ocupa vão influenciar na leitura.

Com a propagação de tecnologia nos anos 90, o autor e o leitor foram gradativamente sendo substituídos pelo computador e pelo usuário, ponto que fortaleceu os estudos sobre as temáticas interação humano-computador (IHC). Os textos que seriam utilizados para o meio virtual teriam que ser tratados diferentemente da maneira que eram utilizados para publicações impressas. Agora seriam estudadas maneiras de se dispor o conteúdo sobre o layout de página na web, tendo o usuário um papel fundamental para o desenvolvimento desse campo de estudos.

Os meios digitais vieram para afirmar o nascimento de um novo usuário como ponto de partida para novos paradigmas no campo do design.

Projete uma interface homem-máquina de acordo com as habilidades e as fraquezas da humanidade, e você terá ajudado o usuário não apenas a realizar uma tarefa, mas a ser alguém mais feliz e produtivo (RASKIN, 2000).

\section{USABILIDADE/LEGIBILIDADE E EXPERIÊNCIA PARA NOVAS MÍDIAS}

Em seu texto, Lupton (2006) diz que o usuário tem mais dificuldade para ter uma leitura longa na tela do computador do que quando comparado a um livro. Ela assume que o usuário tem expectativas diferentes em relação ao computador, uma vez que tudo muda em questão de um clicar em uma imagem ou em um link. No caso do computador, o usuário buscaria mais a produtividade do que contemplar o 
conteúdo. Dessa maneira, o meio digital transforma a leitura desse usuário e a legibilidade entra com grande força nesse meio, mudando a estética da tipografia que anteriormente era usada para o texto impresso (LOPEZ, 2000).

Outra experiência que os meios digitais proporcionaram ao usuário foi a possibilidade de interagir de maneira mais direta com iconografia. Esses elementos começaram a ser usados como forma de comunicação rápida com o usuário, uma vez que as informações poderiam ser resumidas em apenas um símbolo, dando praticidade ao visitante da página. Proporcionou também a possibilidade de criação de símbolos universais que substituíam as inúmeras traduções de cada língua (LUPTON,2006). A adoção dessas simbologias também se deveu, ainda, aos fatores de limitação espacial das páginas e a necessidade de uma comunicação mais direta e específica com os usuários.

\begin{tabular}{|c|c|c|}
\hline 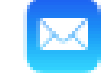 & Mail, Contacts, Calendars & $>$ \\
\hline$\Longrightarrow$ & Notes & $>$ \\
\hline$\vdots$ & Reminders & $>$ \\
\hline & Phone & $>$ \\
\hline & Messages & $>$ \\
\hline 口a & FaceTime & $>$ \\
\hline ब. & Maps & $>$ \\
\hline
\end{tabular}

Figura 1 - Figura de exemplo de iconografia - iOS Human Interface Guidelines. Retirado do guia da Apple Online

Com a grande difusão dos meios digitais na cultura da população mundial, vários estudos foram iniciados nesse campo visando uma melhor experiência para o usuário. Na tipografia, estudos foram voltados para a legibilidade, para os espaçamentos, entrelinhamento e alinhamento (LUPTON, 2006). A partir da evolução do meio e sua utilização cada vez mais frequente por uma quantidade cada vez maior de usuários, as informações não poderiam mais ser dispostas de qualquer maneira, o planejamento e a modelagem faziam parte agora dos estudos dos designers aplicados ao digital.

Para facilitar a utilização de textos na web, foi criada uma hierarquia que veio com o objetivo de enfatizar alguns conteúdos, organizando melhor a leitura do usuário e facilitando a legibilidade dos conteúdos em ambientes virtuais. Por meio do HTML esses elementos puderam ter essa hierarquização e uma melhor organização na tela (LUPTON, 2006), como mostrado na imagem abaixo: 

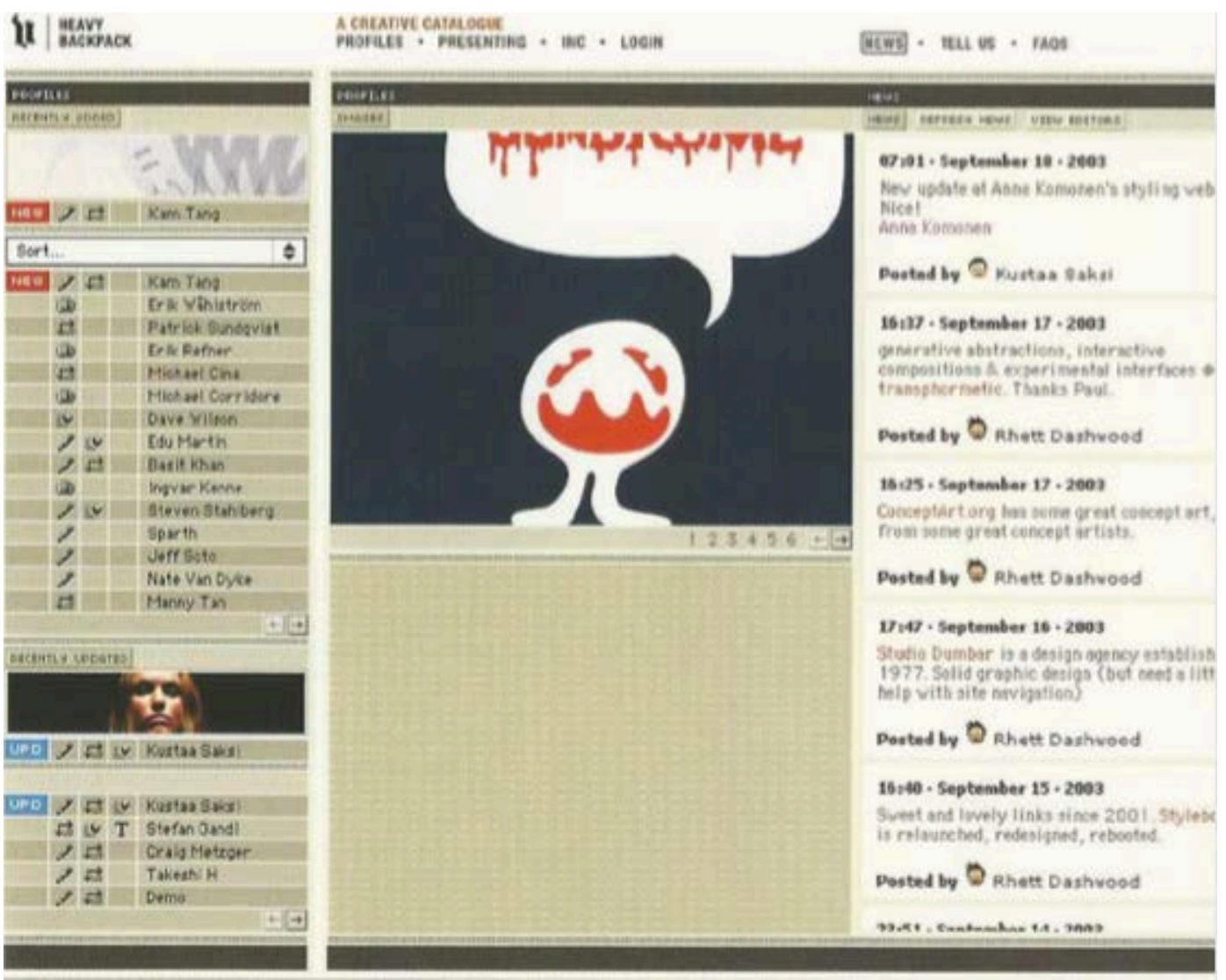

Figura 2 - Heavy Backpack site, 2003 - Retirado do livro Pensar com Tipos

Após alguns anos, com o surgimento de smarthphones e tablets possibilitou o acesso à web. Contudo esse acesso apresentava particularidades em relação aos tamanhos de tela, variação de formatos, velocidades de carregamento, fazendo com que o conteúdo passasse por outra transformação e assim a tipografia também mudaria significativamente. O sistema de folhas em estilo cascatas (CSS) foi uma ferramenta que ganhou grande valor nesse período, já que possibilitava aos designers planejarem o layout para diferentes equipamentos (DA SILVA, 2014).

\section{OS AVANÇOS DA TIPOGRAFIA NA ERA DIGITAL E A RETÓRICA TIPOGRÁFICA}

Com o surgimento da era tecnológica a tipografia sofreu um recuo, os primeiros computadores possibilitavam apenas fontes pixelizadas e mesmo após os avanços da tecnologia inicial, as fontes se limitavam à memória daquela ferramenta (SILVA E FRAGOSO, 2004). Apesar de proporcionar aos designers criar e reproduzir antigas fontes agora nos meios digitais, os sites e textos disponíveis na web estavam limitados às fontes que estavam instaladas no computador. Elas eram chamadas de safe fonts e dominaram o mercado digital por serem fontes que já vinham instaladas na própria máquina.

$\mathrm{Na}$ visão da tipografia impressa, o computador ampliou as possibilidades de criação de novos tipos e novas disposições deles em um layout, mas ao mesmo tempo fortaleceu a pirataria tipográfica no meio digital (DA SILVA, 2015). Observando-se os dois lados que a tecnologia proporcionou, a mais prejudicada foi a tipografia para utilização na web, que ficou limitada por vários anos até surgirem ferramentas como o 
CSS e o Flash, sendo esse último mais difícil de ser usado pela sua dificuldade de integração com o HTML (SILVA E FRAGOSO, 2014).

Mesmo com a adequação dessas ferramentas, em 1990 pela Adobe, para possibilitar uma maior liberdade para as fontes, hoje ainda designers estão sujeito às fontes disponibilizadas pela mesma (DA SILVA, 2015), ou pela Typekite e o Google Fonts. Como na imagem a seguir:

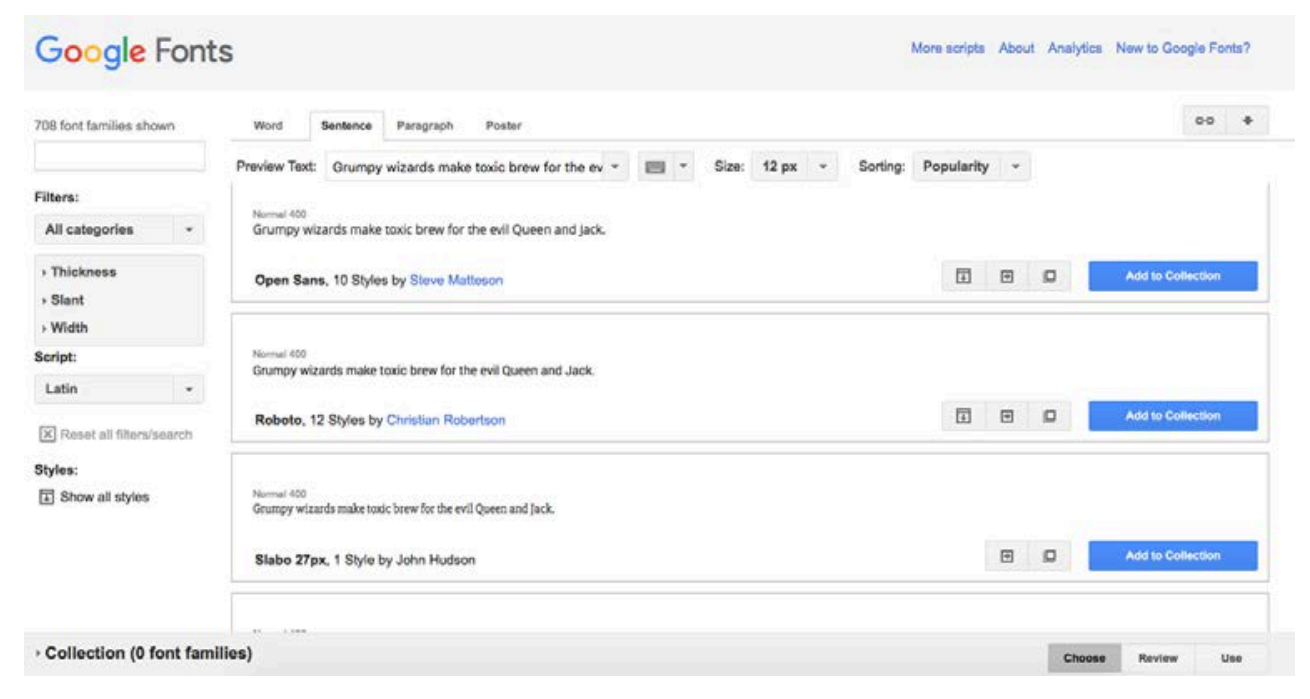

Figura 3 - Figura do Google Fonts - Retirado do site Google Fonts

Quais seriam então as ferramentas que possibilitariam o desprendimento da tipografia dessas ferramentas? O software fonts quirrel que é disponibilizado na internet possibilita alguns recursos para tentar fugir dessas limitações, porém ainda se encontram um pouco limitado.

Segundo Brumberger (2003), a retórica visual consistia em mudanças propostas ao que já estava sendo usado, a retórica se referia a uma quebra de paradigma. Essa retórica visual teve uma maior importância com a entrada da comunicação no meio digital e a tipografia tornou-se parte dessa retórica. Então se estamos limitados em parte em relação à utilização da mesma na web, estamos limitando novas ideias, novas vertentes e novas maneiras de manipulação do signo.

Com a herança cultural das safe fonts, a tipografia no meio digital ficou presa a antigos estilos que influenciaram e influenciam até hoje as fontes que são disponíveis para utilização (SILVA E FRAGOSO, 2014). Além dessa herança notamos também que há uma influência do mercado e da influência para unificação da tipografia na comunicação que ainda faz que o tipo ainda seja tão limitado.

\section{CONCLUSÃO}

De acordo com a pesquisa bibliográfica, a tipografia quando entrou no meio digital, conseguiu avanços em relação à produção impressa possibilitando cada vez mais a sua manipulação e o forte crescimento de novos tipos. Anteriormente quando ainda estava na produção manual, existia certa limitação para a produção de novos tipos e o processo era demorado.

A entrada do computador agilizou o processo de criação, proporcionou novas ferramentas, novos programas e a possibilidade de digitalizar ideias que antes eram 
feitas no papel. Além de todos esses ganhos, o computador permitiu o livre acesso a qualquer pessoa a esses tipos de ferramentas para a criação, tornando a criatividade do designer ou uma pessoa comum, o limite para a criação de signos.

Os ganhos foram incontáveis para a utilização digital, porém algumas dificuldades foram encontradas quando a utilização da tipografia passou para a web, mesmo com a criação de ferramentas para tentar ajudar a manipulação dos tipos, concluímos que a tipografia não tem total liberdade para agir na web. A tipografia ainda é fortemente limitada pelas ferramentas de criação de sites e também limitada pela influencia do mercado e pela intenção de unificar a tipografia na comunicação. 0 designer acaba perdendo a possibilidade de trazer novas ideias de interação entre tipografia e layout para o ambiente na web.

Nessa pesquisa bibliográfica também notamos o quanto a cultura das safes fonts influenciou por décadas e quanto ainda hoje tem influência sobre as fontes que são disponibilizadas para utilização na web, impactando fortemente o trabalho do designer para a criação de layouts com a utilização de tipografias diferentes. Essa limitação faz com que grande parte das páginas na internet utilizem a mesma fonte para criação, como exemplo a ampla utilização da fonte helvética.

Uma possibilidade para continuidade de estudo, seria a criação de ferramentas que possibilitassem ao designer utilizar quaisquer fontes ou até mesmo fontes de sua própria autoria na web. Um estudo voltado para facilitar a utilização de tipos da web de forma segura e de forma que não traga mais trabalho para o desenvolvedor.

\section{REFERÊNCIAS}

BARTHES, Roland. A morte de autor. In: O Rumor da Língua, São Paulo, 2004.

BRAGA, Joaquim. Formas imagéticas e formas discursivas. Revista filosófica de Coimbra, Coimbra, v. 37, p. 149-174, 2010.

BRUMBERGER, EVA R.. The Rhetoric of Typography: The Persona of Typeface and Text. Technical Communication, [S.L], v. 50, n. 2, p. 206-223, mai. 2003.

CAUDURO, Flávio Vinicius. Desconstrução e tipografia digital. Arcos, Rio de janeiro, v. único, n. 1, 1998.

DA SILVA, Dennis, imagem, reprodução e representação da cultura tipográfica na web. In: P\&D DESIGN - CONGRESSO BRASILEIRO DE PESQUISA E DESENVOLVIMENTO EM DESIGN, 11. 2014, Gramado.

DA SILVA, Dennis, A influência da cultura impressa nos tipos digitais das primeiras GUIs. In: anais CIDI - Information Design International Conference, 7. 2015.

DA SILVA, Dennis; FRAGOSO, Suely, Aspecto e herança cultural das Safe Fonts na web. In: Infodesign - Revista Brasileira de Design da Informação, São Paulo, v.11, n.3, p. 291-304, 2014.

EIS, Diego. Propriedade @font-face CSS - Fonts externas na web. 2010. Disponível na internet por http em: < http://tableless.com.br/font-face-fonts-externas-na-web/>. Acesso em 30 abril 2016.

FONSECA, Joaquim da. Tipografia \& Design Gráfico - Design e Produção de Impressos e Livros. 1 ed. Brasil: Bookman, 2008. 280p. 
iOS Human Interface Guidelines. 2016. Disponível na internet por http em: < https://developer.apple.com/library/ios/documentation/UserExperience/Conceptual/ MobileHIG/Applcons.html\#//apple_ref/doc/uid/TP40006556-CH19-SW1>. Acesso em 29 de abril de 2016

LOPEZ, Fabio. Tipografia de texto: pesquisa, planejamento e construção. 2000. 118 f. Projeto (Graduação). Universidade do Estado do Rio de Janeiro - Centro de Ciências e Tecnologias.

LUPTON, Ellen. Pensar com tipos. São Paulo: Cosac \& Naify, 2006. 184 p.

MEGGS, Philip B, PURVIS, Alston W. História do design gráfico. 1 ed. Cosac \& Naify, 2009. 720 p.

MIGLIARI, Mirella De Menezes; NOJIMA, Vera Lúcia M. Dos Santos. Tipografia 'desconstrucionista' e o modelo triádico de Peirce. InfoDesign Revista Brasileira de Design da Informação, São Paulo, v. 4, n. 1, p. 20-28, 2007.

NÖTH, Wienfried. Panora da semiótica de Platão a Pierce. São Paulo, 1998.

PINHEIRO, Gustavo. Mesclagem e contiguidade na imagem publicitária impressa: 0 papel da metáfora e da metonímia na mensagem visual persuasiva. 2011. $315 \mathrm{f}$. Tese (doutorado). Universidade Federal da Bahia Faculdade de Comunicação, Programa De Pós-Graduação em Comunicação e Cultura Contemporâneas.

POYNOR, Rick; HELFAND, Jessica. Textos clássicos do design gráfico. 1 ed. WMF Martins Fontes, 2010. 336 p.

VASCONCELOS, Priscila. Tipografia para web. 2015 . Disponível na internet por http em: <http://www.designculture.com.br/tipografia-para-web/>. Acesso em 28 abril 2016. 